\title{
Metaphors We Teach By: \\ Examining Teacher Conceptualizations of Literacy in the English Language Arts Classroom
}

\author{
CONNIE KENDALL THEADO \\ University of Cincinnati
}

\begin{abstract}
This case study used metaphor analysis to gain insight on the conceptualizations of literacy informing six English Language Arts educators' understanding of the meaning and goals of U.S. literacy education today. While findings indicated literacy's functional aspect as the most prominent metaphoric conceptualization employed, the teachers' use of alternate metaphors to highlight the value of literacy learning beyond its pragmatic outcomes suggests that U.S. literacy education reform may be out of step with the pedagogical goals teachers have for their students. The article concludes with a discussion of the pedagogical implications suggested by the study findings.
\end{abstract}

It is important to see that we don't just talk about arguments in terms of war. We can actually win or lose arguments. We see the person we are arguing with as an opponent. We attack his positions and we defend our own. ... Though there is no physical battle, there is a verbal battle, and the structure of an argument reflects this. It is in this sense that the ARGUMENT IS WAR metaphor is one that we live by in this culture: it structures the actions we perform in arguing.

Lakoff \& Johnson (1980, Metaphors We Live By, p. 4)

This investigation into the metaphorical language use of six literacy educators begins by calling to mind Lakoff and Johnson's (1980) famous example, the ARGUMENT IS WAR metaphor. In the passage above, the authors not only dispense with the idea that metaphors are mere figures of speech, but also posit the unconventional standpoint that metaphorical expressions organize the way people think, talk, and act. "The concept of ARGUMENT," they explain, "is partially structured, understood, performed, and talked about in terms of WAR" (p. 5, emphasis in original). Implicit in Lakoff and Johnson's contention that the ARGUMENT IS WAR metaphor is one we "live by" in Western culture is their suggestion that an identifiable relationship exists between an individual's use of metaphorical language and his/her apprehension of and participation in social reality. Plainly put, metaphorical expressions do not simply reflect reality, but instead partially constitute that reality. And while Lakoff and Johnson are careful to avoid the argument that words alone can radically or permanently alter reality, their theory is clearly 
guided by the premise that links changes in our conceptual systems to changes in our perceptions of the world and, in turn, our actions in it.

By any measure, Metaphors We Live By (1980) is an important scholarly contribution to the field. Lakoff and Johnson's claim that the investigation of metaphorical language helps researchers "study the nature of metaphorical concepts and gain an understanding of the metaphorical nature of our activities" (p. 7), encourages the application of metaphor analysis along numerous lines of inquiry, and has recently generated interest among those seeking to understand how conceptualizations of literacy impact the teaching-learning transaction (Armstrong, 2008; Levin \& Wagner, 2006; Paulson, 2006). The purpose of this case study was to gain insight on how conceptualizations of literacy may be informing teachers' understandings of the meaning and goals of literacy education today by analyzing the metaphors used by six English Language Arts educators to describe their histories as readers and writers, their understanding of the values and utilities of literacy for individuals and society, and their daily work with literacy learners in the classroom.

The influence conceptualizations of literacy has on the formation of educational goals, policies, and practices was introduced by Scribner (1984/1988) in her article, "Literacy in Three Metaphors," published at the height of U.S. concern about a national literacy crisis. The critical connection Scribner asserted, that the way we think about literacy-what literacy is, what we expect literacy can do for individuals and societies-shapes "the substance and style of educational programs" (p. 71), not only underscored the competing sociopolitical values associated with achieving literacy, but also revealed the various metaphors used by educational researchers and policymakers to advance those values. The theoretical framework that emerged from Scribner's analysis, a taxonomy identifying three literacy metaphors dominating late $20^{\text {th }}$ century U.S. educational discourse, proved significant as well, enabling other researchers to clarify the relationship between how we conceive literacy and how those conceptualizations promote certain educational goals and underwrite the development of literacy programs, policies, and standards (Cervero, 1985; Ilsley \& Stahl, 1993; Keller-Cohen, 1993; Malicky \& Norman, 1995; Mason \& Allen, 1986).

What's missing in Scribner's (1984/1988) influential study are the voices of practitioners; that is, how teachers conceptualize literacy in relation to the competing social, political, and institutional values associated with its acquisition and use, and what those conceptualizations might suggest about the metaphorical nature of literacy education in U.S. classrooms. This study addresses the gap that often opens between the voices of educational researchers or policymakers and the voices of teachers about the meaning of literacy and the goals for literacy education. As a qualitative research methodology that helps researchers gain insight into an individual's understanding of a particular concept, like literacy, metaphor analysis is useful for re-asserting the perspectives of teachers in these consequential conversations.

Lakoff and Johnson's (1980) contention that "argument" is partially structured, understood, performed, and talked about in terms of "war" provides a useful point of entry, as does their suggestion that the ARGUMENT IS WAR conceptual metaphor is one we "live by" in the West. For, if the metaphorical relationship between argument and war can be articulated with regard to their conceptual overlap, the principle function of metaphor where "one kind of thing is understood in terms of another" (p. 5), other metaphorical relationships may be similarly articulated. The perception of a U.S. literacy crisis - a powerful metaphoric construction in its own right - that precipitated Scribner's (1984/1988) article nearly three decades ago remains largely unabated. In the intervening years, the idea of a U.S. literacy crisis has become an 
available discourse (Trimbur, 1991), a persuasive way to explain educational facts, like falling test scores, and advance reform legislation, including stricter testing requirements for students, increasingly stringent regulations for teacher licensure (Swope \& Minor, 2000), and the recently adopted Common Core State Standards (Heller \& Greenleaf, 2007; Salinger, n.d.). Like the ARGUMENT IS WAR metaphor, which has become so commonplace as to assume a naturalized position in the West's conceptual system, the metaphorical link between "literacy" and "crisis" has also become naturalized in the U.S. consciousness, influencing the ways in which we understand, talk about, and perform literacy education in the new millennium. Thus, the extent to which Scribner's taxonomy may yet provide a viable explanatory framework for understanding the meaning of literacy in relation to current U.S. educational goals and classroom practices is a key question compelling this inquiry.

Using metaphor analysis (Cameron \& Low, 1999; Cortazzi \& Jin, 1999; de Guerrero \& Villamil, 2002; Kovesces, 2002; Littlemore \& Low, 2006; Low \& Todd, 2010; Paulson \& Armstrong, 2011), this case study examined six English Language Arts teachers' conceptualizations of literacy in order to better understand the metaphorical nature of K-12 literacy education today, a means of discovering what might be called the metaphors we "teach by." The following questions guided the study's design: (1) What conceptualizations of literacy are operating in the teachers' descriptions of and attitudes toward literacy and literacy education?; (2) To what extent, if any, are the three literacy metaphors identified in Scribner's (1984/1988) taxonomy apparent in the teachers' language use?; and (3) What pedagogical implications might be suggested by the findings?

Beginning with an overview of the theoretical frameworks through which the study data were viewed, this article moves to a discussion of the four prominent conceptual metaphors for literacy found in the data sets, using Lakoff and Johnson's (1980) theory for interpreting the findings in relation to the participants' situational contexts and experiences. The article concludes by highlighting the pedagogical implications suggested by the findings, noting the potential for re-imagining the goals of K-12 literacy education in light of alternate metaphors we might teach by in the future.

\section{Theoretical Frameworks and Relevant Literature}

\section{Constructivist Sociocognitive and Cognitive-linguistic Perspectives on Language Use}

The theoretical framework informing this case study is two-fold. First, it relies on a sociocognitive perspective regarding the study of language use (Condor \& Antaki, 1997; Flower, 1994), which views acts of thinking as situated constructions concomitantly shaped by interior processes and exterior social forces. As Flower explains, a sociocognitive approach to the study of language is critical in that "neither social nor cognitive theory makes genuine sense without the other [because] we cannot isolate the social process from the minds that carry it out" (p. 33). The sociocognitive approach is further supported by social constructivist logic. Flower writes:

In talking about cognition, I refer to acts of thinking (e.g., interpreting, problem solving, reflecting) that go on, in real time, in the minds of individuals ... Such a cognition, however, does not exist in a vacuum. The interpretations and knowledge [individuals] construct is their own, but it is built out of and in response to other voices, prior texts, social expectations, and ideological alternatives. (p. 31) 
Condor and Antaki (1997) share Flower's (1994) constructivist sociocognitive orientation to language study and posit its usefulness for understanding the meaning of spoken and written discourse. In contrast to the traditional mentalist orientation, which "treats the subjects' responses to researchers' questions as reports of inner mental processes (whether 'mindful' or more automatic)," the constructivist orientation "treats people's talk ... as public actions which may serve a number of social functions" (Condor \& Antaki, 1997, p. 320). This distinction, drawn between the mentalist's conception of language use as "private cognitive reports" and the constructivist's conception of language use as "public communicative acts" ( $p$. 329), supports Condor and Antaki's larger assertion that acts of thinking (e.g., perception, interpretation, evaluation, reflection) are discursive rather than merely cognitive phenomena. For Condor and Antaki, cognition is "bound up in action: playing out identity, constructing social reality" (p. 335). The constructivist sociocognitive perspective thus provides an important theoretical framework for this study, where the participants' discourse is understood as situated and social, and cognition is viewed as a dynamic integration of interior processes and exterior forces.

Second, this study draws on the theoretical perspective of cognitive linguists (Lakoff \& Johnson, 1980; Kovesces, 2002) in which the use of metaphors is viewed as indicative of an individual's deeply held conceptualizations about a given topic, and language is seen as a means of organizing both our perceptions of and active participation in situations and events. "Our ordinary conceptual system, in terms of which we both think and act," Lakoff and Johnson write, "is fundamentally metaphorical in nature. ... Since communication is based on the same conceptual system that we use in thinking and acting, language is an important source of evidence for what that system is like" (p. 3). The investigative research approach of metaphor analysis employed here is informed by the cognitive-linguistic perspective of language use, both in the collection of naturally occurring metaphorical linguistic expressions found in the teachers' spoken and written language and in the subsequent categorization of the conceptual metaphors about literacy emergent in the analysis.

\section{Scribner's Taxonomy: Literacy in Three Metaphors}

Because a goal for this study was to examine the extent to which Scribner's (1984/1988) taxonomy may yet hold explanatory power for understanding conceptualizations of literacy in U.S. educational contexts today, it also served as a key theoretical framework through which the data were viewed. Scribner's article, "Literacy in Three Metaphors," was situated squarely within the national panic that ensued after the National Commission on Excellence in Education (1983) released A Nation at Risk: The Imperative for Educational Reform, itself a document fraught with metaphor (see Brickell, 1983; Cawelti, 1983; Hlebowitsh, 1990). Although A Nation at Risk was published three decades ago, Hunt and Staton (1996) argued that no single report has been as influential in advancing U.S. reform legislation between 1983 and the 1994 passage of the Goals 2000: Educate America Act, the forerunner of the 2001 No Child Left Behind Act that serves as the framework for today's standards-based education. In other words, despite the thirty years that have passed since the publication of these well-known "prior texts" (Flower, 1994, p. 31), each has importantly shaped the broader ideological contexts within which literacy, as a concept, and K-12 literacy education, as a sociopolitical imperative, is currently talked about, thought about, and enacted. 
The U.S. literacy crisis ignited significant controversy about the meaning of literacy. In response, Scribner (1984/1988) organized her discussion around three prominent metaphorsLITERACY AS ADAPTATION, LITERACY AS POWER, and LiterACY AS A STATE OF GRACEremarking that each metaphor is grounded in specific educational, political, and epistemological assumptions about literacy "as a social good, as well as a social fact" (p. 72). According to Scribner, the LITERACY AS ADAPTATION metaphor is "designed to capture the concepts of literacy that emphasize its survival or pragmatic value" (p. 73), an essentially individualistic enterprise. Contrastively, the LITERACY AS POWER metaphor is concerned with notions of liberation and social change and "emphasizes a relationship between literacy and group or community advancement" (p. 75), while the LITERACY AS A STATE OF GRACE metaphor conceptualizes the literate individual's life as "deriving its meaning and significance from intellectual, aesthetic, and spiritual participation in the accumulated creations and knowledge of humankind, made available through the written word" (p. 77). Rooted in disparate assumptions about literacy's sociopolitical values, Scribner observed that each metaphor is problematic, especially with regard to its educational implications, in that they all suggest that "literacy is a kind of reality that educators should be able to grasp and explain" (p. 72). Scribner's remark, that metaphorical representations of literacy promote varying perceptions of reality, is relevant here and reinforces Lakoff and Johnson's (1980) standpoint: Metaphors actively structure our conceptual systems that, in turn, influence our worldview and shape our participation in society.

Scribner's (1984/1988) article, specifically her concern with the relationship between literacy metaphors and educational policymaking, has been regularly cited in the scholarship. Cervero (1985) employed Scribner's descriptions of literacy metaphors to examine the dangers of what he termed the "totalizing effects" (p. 51) of metaphorical definitions for adult literacy programs. Mason and Allen (1986) adapted Scribner's metaphor approach to describe the various conceptual frameworks associated with the emergent literacy practices of school-aged children. Keller-Cohen (1993) referred to Scribner's essay in an effort to support her claim that metaphorical conceptions of literacy are always shifting and historically contingent. Ilsley and Stahl (1993) extended Scribner's methodology to include the public uses of literacy metaphors, especially within the media of political speeches and the popular press. And Malicky and Norman (1995) applied Scribner's theoretical framework to their investigation of the ways in which literacy educators and adult learners conceptualize the purpose of community literacy programs.

More recently, Williams (2003) cited Scribner's (1984/1988) LITERACY AS ADAPTATION metaphor, with its emphasis on literacy as a technical skill, as one of eleven major theses informing research in computer literacy and information technology fluency. Sutherland (2010) called upon Scribner's theory to trouble the metaphors used to construct student identities in Writing across the Curriculum discourse. Additionally, Bhattacharya (2011) referenced Scribner's essay to problematize the ways in which Western conceptualizations of literacy work to standardize and stabilize its meaning for today's researchers.

\section{Methods}

This research employed a qualitative case study approach, defined by Merriam (1988) as "an intensive, holistic description and analysis of a single entity, phenomenon, or social unit" ( $p$. 16). While case study is an evolving field in social science research, "variously defined as a method, methodology, or research design" (VanWynsberghe \& Khan, 2007, p. 80), there is general agreement that case studies are "particularistic, descriptive and heuristic, and rely heavily 
on inductive reasoning in handling multiple data sources" (Merriam, p. 16). VanWynsberghe and Khan's proposed re-definition of case study as a "transparadigmatic and transdisciplinary heuristic that involves the careful delineation of the phenomena for which evidence is being collected (event, concept, program, process, etc.)" (p. 80) highlights the interplay between the case itself and the unit of analysis as discovered or constructed during the research process, establishing a good fit with metaphor analysis as a qualitative research method.

Metaphor analysis was used to gain insight on how conceptualizations of literacy may be informing teachers' understandings of the meaning and goals of literacy education in light of the social, political, and institutional values associated with its acquisition and use today. As an investigational research tool, metaphor analysis allows for the study of metaphorical linguistic expressions naturally occurring in participant speech and writing. Using this qualitative approach, data can be described in terms of the conceptual categories that are meaningful for participants of specific discourse communities; in this case, six K-12 literacy educators.

Like all qualitative descriptive research, case studies and metaphor analyses are limited in their ability to make claims beyond the immediate research context. In particular, this case study is limited by the small size of the data set and the lack of data set triangulation with classroom observations. The possibility of interpretive bias, or what Armstrong, Davis, and Paulson (2011) call "the subjectivity problem" (p. 153), is also a study limitation. Because metaphors are "formed through various social and cultural networks" (p. 152) and, thus, function variously across these contexts dependent on an individual's use of the metaphor, Armstrong, Davis, and Paulson stress the importance of having an "intentional plan" for data verification built into the study design to support the researcher's interpretations and reduce bias (p. 153).

\section{Participants}

Purposive sampling (Patton, 2001), using a specific criterion for identifying participants, informed the recruitment process. The criterion in this case was that participants needed to be inservice English Language Arts teachers with three or more years of classroom experience. Six teachers, three female elementary school teachers and three secondary school teachers, two female and one male, participated in the study. The three elementary school teachers-Mary, a first-grade teacher with eight years of experience; Sarah, a second-grade teacher in her twelfth year of teaching; and Anne, a third-grade teacher beginning her fourth year-comprised Focus Group A. The three secondary school teachers who comprised Focus Group B-Molly, Rob, and Jane - are veteran teachers with seventeen or more years of experience each, and have taught a variety of grade levels and courses. All participants are identified by pseudonyms.

To elicit metaphorical descriptions of the concept of literacy and their work as literacy educators, participants completed a written survey individually and then joined a three-person, 90-minute focus group session to discuss the topic. The written survey (Appendix A) consisted of five short-answer questions to activate each teacher's awareness of his/her personal experiences with literacy, and to elicit attitudes and perceptions of literacy as a social, political, and educational concept. The two focus group sessions, held separately, centered on seven openended questions (Appendix B) designed to overlap with the written survey questions for triangulation purposes. Because this study's primary aim was to discover teacher conceptualizations of literacy and their understanding of the goals of literacy education, no provisions were made to collect classroom data. 


\section{Data Sources and Analysis}

Data sources included the six participants' written surveys and two sets of observational field notes gathered during the two separate, audio-taped, 90-minute focus group sessions. Metaphor analysis involves collecting and examining the actual spoken or written metaphors used by the participants, known as metaphorical linguistic expressions, in order to identify conceptual metaphors, or the underlying analogic conceptualizations, that can provide insight into participants' understandings of a particular topic (Cameron \& Low, 1999; Kovesces, 2002; Paulson \& Armstrong, 2011). While procedures may vary, Armstrong, Davis, and Paulson (2011) reported these steps common to metaphor analysis studies:

1. Gather metaphorical linguistic expressions from participants

2. Identify source and target domains of the metaphor

3. Identify source features of the metaphor

4. Map source features onto the target

5. Develop conceptual metaphors based on the resulting mappings

6. Identify entailments of the conceptual metaphor source

7. Identify hidden features of the conceptual metaphor source

8. Identify themes in patterns of conceptual metaphors (p. 160)

The metaphorical linguistic expressions appearing in the data sets were analyzed for the relationship between the source domain and the target domain in order to map analogical correspondences between the two. In metaphor analysis, the source domain is defined as the conceptual domain from which a person constructs metaphorical expressions, and the target domain is defined as the conceptual domain that the person is trying to understand. For example, in the metaphorical linguistic expression one of the participants used, "Literacy is about functioning in society," the idea of "functioning" in society serves as the source domain through which the teacher understands the target domain "literacy."

Metaphorical entailments, which carry particular aspects of the source domain to the target domain by logical means, were also analyzed. For example, the metaphorical linguistic expression used by another participant, "Oppression gets overturned through literacy education," derives from the premise that literacy education is a means of empowerment, a logic congruent with the LITERACY AS POWER conceptual metaphor. The conceptual metaphors reported here were based on the results of this analogical mapping process, and then categorized according to the themes in the patterns that emerged. Metaphor checking (Armstrong, Davis, \& Paulson, 2011, p. 154), in which the researcher inserts a "reiteration question" or asks a participant to further elaborate or clarify comments, was used periodically throughout the focus group sessions for data verification purposes. Thematic triangulation (Armstrong, Davis, \& Paulson, 2011, p. 156), where both types of data sources were revisited during the mapping process to confirm or disconfirm source and target domains, track their frequency of use, and check initial interpretations of emergent conceptual metaphors and themes, provided an additional verification method. Field note data and transcribed audio recordings were used to triangulate written survey data.

Specific to the goals of this study, the conceptual metaphors identified were viewed through Lakoff and Johnson's (1980) theoretical perspective that conceptual systems are "fundamentally metaphorical in nature," and that "language is thus an important source of evidence" for what those systems are like (p. 3). Two attendant claims about how metaphors serve as indicators of conceptual systems were used as critical lenses through which the study findings are described and discussed: (1) "The very systematicity that allows us to comprehend 
one aspect of a concept in terms of another (i.e., metaphor) will necessarily hide other aspects of that concept" (p. 10) and (2) "The most fundamental values in a culture will be coherent with the metaphorical structures of the most fundamental concepts in a culture" (p. 22). Just as metaphor analysis is effective for going beyond the surface of spoken or written language to identify conceptualizations indicated by metaphorical linguistic expressions, Lakoff and Johnson's theory provides a useful explanatory framework for interpreting the data in relation to the situational contexts and experiences of the participants.

\section{Discussion}

\section{The Fundamentally Metaphorical Nature of Conceptual Systems}

Two questions invited participants to begin writing/talking about how they think about literacy and what they do as literacy educators. When asked to describe their personal histories as literacy learners (Question 2; Appendix A), all wrote that they had been successful students. Mary, Sarah, Anne, and Jane credited specific teachers for their successes with literacy, while Rob and Molly credited their parents. Although each teacher defined literacy as "the ability to read and write," only two cited memories of being "talented" writers while all six recalled memories of being "avid" readers. Thus, for these teachers, the ability to read seemed to define literacy more often than did the ability to write. In addition, reading was unanimously described as "pleasurable," something that Jane, Molly, and Sarah figuratively linked with the concept of love. Jane wrote that she has a "great love of literature;" Molly remarked that she "fell in love with literature;" and Sarah viewed herself as a "lover of books." When writing was mentioned, it was conceptualized only as a private expression of self, as in Jane's comment about writing "poetry to express myself" or Anne's description of her third grade teacher's influence who "encouraged my talent in expressing myself as a writer." With respect to how the teachers think about their own literacy experiences, then, two preliminary claims can be made: (1) literacy was regarded as an important (read: valued, good) enterprise; and (2) their experiences with literacy were often understood as interior or felt experiences, that is, reading as "being in love" and writing as "expressing the self."

When asked why they chose a career in literacy education (Question 1; Appendix B), all six participants described their work as a vocation - "a natural talent" or "a calling" or "a real gift." Sarah and Anne confided that they "always knew" they were "meant to be" teachers, and Rob, who had spent several years working for a family business, described his return to the classroom as "coming back to my life as a teacher." Both Jane and Molly reiterated that they chose to teach English because of their "love affair with reading," and Mary reminisced about the pleasure she receives from "watching non-readers turn into readers by the end of the year." Aligned with their perceptions that literacy is a valuable/pleasurable/felt thing, the participants conceptualized their work as literacy educators in valuable/pleasurable/vocational terms, as well. Their use of metaphorical linguistic expressions, like Rob's experience of "coming back to my life as a teacher" or Jane and Molly's "love affair with reading," suggest the fundamentally metaphorical nature of conceptual systems that Lakoff and Johnson (1980) posit.

\section{The Systematicity of Metaphors: Highlighting and Hiding Aspects of a Concept}

In response to Question 3 (Appendix A), all participants defined literacy as "the ability to read and write," the denotative aspect of literacy. However, four of the six teachers qualified their definitions in order to differentiate between the meaning of literacy and the meaning of 
what they termed "real" literacy. Molly, Anne, and Jane defined "real" literacy as "functioning in society," and Sarah added that "real" literacy means "that you can get along in the worldreading and writing, functioning, surviving." Further, during the discussion of Question 2 (Appendix B), all six teachers identified the conceptual split-literacy v. "real" literacy-as a meaningful one for defining literacy, but then each quickly dismissed literacy's denotative aspect altogether, noting that "it doesn't really count" and "it's not really the meaning of literacy." That the denotative aspect of literacy was unanimously regarded as unreal, while the "real" meaning of literacy was conceptualized metaphorically is a telling conversational feature. The implication is that metaphors operate in the ways Lakoff and Johnson (1980) suggest: They actively structure our conceptual systems and influence our perceptions of reality, or what's real and unreal.

Questions on both the written survey and in the focus group sessions asked participants to identify abstract values and utilities associated with becoming a literate member of society. Table 1 identifies the four conceptual metaphors used by the teachers, as well as the frequency with which these metaphors occurred during the two focus group discussions.

Table 1

Frequency of Conceptual Metaphors Occurring in Teacher "Talk"

\begin{tabular}{|c|c|c|c|}
\hline $\begin{array}{c}\text { Conceptual Metaphors } \\
\text { Employed }\end{array}$ & Focus Group A & Focus Group B & $\begin{array}{c}\text { Combined Focus } \\
\text { Groups }\end{array}$ \\
\hline $\begin{array}{c}\text { LITERACY AS } \\
\text { ADAPTATION }\end{array}$ & 19 & 17 & 36 \\
\hline $\begin{array}{c}\text { LITERACY AS } \\
\text { POWER }\end{array}$ & 0 & 4 & 4 \\
\hline $\begin{array}{c}\text { LITERACY AS A } \\
\text { STATE OF GRACE }\end{array}$ & 2 & 8 & 10 \\
\hline $\begin{array}{c}\text { LITERACY AS } \\
\text { PLEASURE* }\end{array}$ & 12 & 0 & 12 \\
\hline
\end{tabular}

Note. Focus Group A = Elementary Teachers; Focus Group B = Secondary Teachers. *Denotes alternate conceptual metaphor not found in Scribner's (1984/1988) taxonomy.

The following statements are examples of metaphorical linguistic expressions as they correlate with the conceptual metaphors reported in Table 1. In metaphor analysis research, conceptual metaphors are typically reported in ALL CAPS. Metaphorical linguistic expressions are typically reported in italics.

LITERACY AS ADAPTATION:

(Anne) "Literacy is about functioning in society."

(Sarah) "Literacy means that you can get along in the world-reading, writing, functioning, surviving."

LITERACY AS POWER:

(Rob) "Knowledge is power. Literacy is a form of knowledge, so literacy is power."

(Jane) "Oppression gets overturned through literacy education."

LITERACY AS STATE OF GRACE: 
(Rob) 'It's important to have knowledge of your culture. As literacy teachers, we pass cultural knowledge down to our students by teaching them to appreciate the literature of the past."

(Jane) "Literacy skills help students connect to the writing of the past, and allows them to appreciate who they are."

LITERACY AS PLEASURE:

(Sarah) "Literacy is not just about 'functioning' in society. It's more about finding personal pleasure through reading, like 'getting lost' in a great book."

(Mary) "Reading is just fun-enjoyable for its own sake."

The data reported in Table 1 are of interest for several reasons. First, the frequent occurrences of Scribner's (1984/1988) three literacy metaphors suggest that these conceptual categories were operational in the language used by the six teachers involved this study. It is also noteworthy that the LITERACY AS ADAPTATION metaphor was particularly frequent, occurring 19 times in Focus Group A and 17 times in Focus Group B, for a total occurrence three times that of any other conceptual metaphor used. The possible reasons for the LITERACY AS ADAPTATION metaphor's primacy will be discussed later.

Second, and consistent with Lakoff and Johnson's (1980, p. 10) assertion that, in their systematicity, metaphors both highlight and hide certain aspects of a concept, the findings indicated that the metaphors, as the teachers employed them, privileged only one aspect of literacy at a time. In other words, an operationalized metaphor highlights one aspect of literacy, like functionality, as it simultaneously hides the other aspects of literacy that are inconsistent with functionality, like power or pleasure. While there was observable shifting among the literacy metaphors during both focus groups' conversations, there was no evidence of blending two or more conceptual metaphors within one metaphorical linguistic expression. The use of one literacy metaphor over another at a particular instance does not mean that the other metaphors cease to exist or inform, either in the immediate conversation or in the larger context of the teachers' conceptual systems. Rather, the non-operationalized metaphors remain in circulation, hidden but still available.

Finally, the findings indicated the occurrence of an alternate conceptual metaphor; namely, LITERACY AS PLEASURE. This conceptual metaphor occurred only in Focus Group A, and was prominent in the elementary school teachers' talk. The LITERACY AS PLEASURE metaphor thus provides an extension of Scribner's (1984/1988) taxonomy and, as such, will become a point of focus later in this article. ${ }^{1}$

\section{Cultural Coherence and Conceptual Metaphors}

The idea that the "fundamental values in a given culture will be coherent with the metaphorical structures of the fundamental concepts in that culture" defines what Lakoff and Johnson (1980) call "cultural coherence" (p. 22). While Lakoff and Johnson acknowledge the heterogeneous nature of any given culture, where diverse value systems exist and sometimes compete, they argue that all cultures generally employ "orientational" metaphors by which particular concepts and sociopolitical values are conceptually linked. An example from Lakoff and Johnson, the up-down orientation, is helpful. The authors write:

\footnotetext{
${ }^{1}$ While the secondary teachers did use the concept of "pleasure" or "enjoyment" in descriptions of their own experiences with literacy (as in "pleasure reading") as well as with regard to why they chose to become literacy educators (as in "I have always enjoyed reading"), none employed the LITERACY AS PLEASURE metaphor when asked either to (a) define literacy or (b) identify the values and utilities associated with literacy. It is this distinction that underpins my claim that the LITERACY AS PLEASURE metaphor operated only within Focus Group A.
} 
Orientational metaphors give a concept a spatial orientation: for example,

HAPPY IS UP; SAD IS DOWN (“I'm feeling up today." Or "I'm feeling low.")

HAVING CONTROL IS UP; BEING SUBJECT TO CONTROL IS DOWN ("I have control over her." Or "He is low man on the totem pole.")

HIGH STATUS IS Up; LOW STATUS IS Down ("She's at the peak of her career." Or "He's at the bottom of the class.")

MORE IS UP; LESS IS DOWN ("My income rose last year." Or "It's too hot; turn the heat down.") (pp. 15-16, emphasis in original)

The up-down orientation was prominent in the teachers' metaphorical descriptions of the abstract values associated with becoming a literate member of society (see Question 4 in Appendix A and Question 3 in Appendix B). For example:

(Anne) "Being literate means you'll be held in high esteem by everyone around you."

(Mary) "Literacy affords you a higher social status; more education equals more status."

(Sarah) "You place yourself in a specific caste by your ability to read or not to read. If you can't read, you'll fall into a lower caste."

(Jane) "If you want to be successful, you'll need a high level of literacy."

(Rob) "Literacy helps you become an informed citizen, an upstanding member of your community."

(Molly) "Being literate means you can rise to the top."

Lakoff and Johnson's (1980) claim reminds us that these metaphorical structures are not arbitrary, but are instead culturally coherent with basic social values (e.g., GOOD IS UP; BAD IS Down). Thus, in the teachers' talk, the up-down orientation of the concept of literacy (e.g., LITERACY IS UP; ILLITERACY IS DOWN) appeared to be culturally coherent with the more general conceptual orientations found in U.S. society.

While the up-down structural orientation of the teachers' metaphorical language about the values associated with literacy was an orientation shared by all participants, each focus group conceptually configured the broader enterprise of literacy education differently (see Figure 1).

FOCUS GROUP A

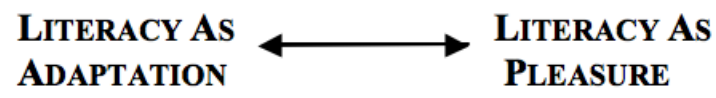

\section{FOCUS GROUP B}

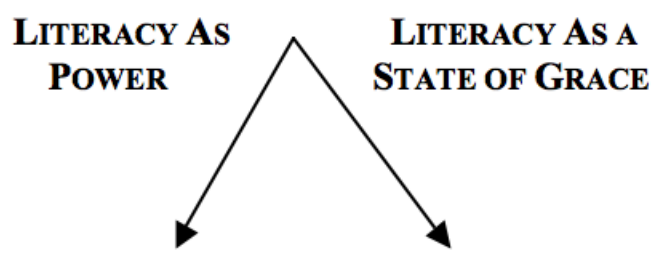

LITERACY As ADAPTATION

Figure 1. Conceptual arrangements of literacy metaphors. This figure illustrates the differing conceptual arrangements between the elementary school teachers (Focus Group A) and the secondary school teachers (Focus Group B). 
Of particular interest here are the dissimilarities between the two configurations with regard to spatial orientation. During their conversation, the elementary teachers (Focus Group A) described their two most prominent conceptual metaphors, LITERACY AS ADAPTATION and LITERACY AS PlEASURE, as end points on a continuum. Contrastively, the secondary teachers (Focus Group B) described the three literacy metaphors within a conceptual hierarchy, with LITERACY AS ADAPTATION situated below both LITERACY AS POWER and LITERACY AS A STATE OF GRACE.

While all cultures employ orientational metaphors, Lakoff and Johnson (1980) assert that "which concepts are oriented which way and which orientations are most important vary from culture to culture" (p. 24). In other words, because value systems differ across cultures and orientational metaphors are relative to a culture's value system, variations in conceptual arrangements are to be expected. A similar argument can also be made for variations in conceptual orientations in relation to the different groups of people that comprise the larger culture. Which social values are assigned priority is partly a matter of an individual's membership within a given community or social grouping and partly a matter of personal values (Lakoff \& Johnson, p. 23). With regard to the differences noted between the teachers' conceptual arrangements, the two focus groups can be seen as representing, to greater or lesser degrees, different professional communities within the more broadly conceived "culture" of education. Viewed in this way, their dissimilar conceptual arrangements may reveal competing assumptions and priorities regarding the values associated with literacy learning as an educational enterprise.

\section{Conceptual continuum.}

Focus Group A's conceptual continuum is representative of what Lakoff and Johnson (1980) term a central-peripheral orientation, or an orientation in which "balance or centrality plays an important role" (p. 24). That is, the central-peripheral orientation situates concepts in a horizontal but oppositional arrangement, like a continuum: When one concept moves toward the center (i.e., increases in social value), the other concept is necessarily pushed to the periphery (i.e., decreases in social value) and vice versa. The orientation focuses on maintaining a balance between the two often-polarized concepts.

Focus Group A's continuum, which positioned the conceptual metaphors of LITERACY AS ADAPTATION and LITERACY AS PLEASURE within a central-peripheral orientation, resonated with the felt tension these teachers reported experiencing in their classrooms as a result of increasing legislative mandates for educational accountability. On this point, Sarah's remarks were instructive: 'Sure, it's very important to teach literacy so that they'll be able to 'function.' We all know that. But, it's just as important that they learn that reading means hours of pleasure. The State doesn't seem to understand that. So, we teach 'em how to be literate ... on grade level." Anne added that she doesn't like to see her students become "frustrated with the fact that they need to read 'on their grade level' rather than choosing any book they'd like. The State wants students to function at pre-determined levels, and that's just unrealistic."

All three elementary teachers described the difficulty of trying to balance the exigencies of the State, which they regarded as teaching the "functional" aspect of literacy, with what they seemed to understand as the more important aspect and value of literacy, to teach literacy as "pleasure." Anne suggested that elementary teachers are "role models for the values of society; to show students how being literate can help you function in the world and become successful." But Sarah quickly interjected: "But we really want them to get a book, and be so excited that they want to read-without being told to-just for fun!" Thus, Focus Group A's conceptual 
arrangement of literacy metaphors along a continuum appeared coherent with the centralperipheral value system they understand as informing their interactions with learners in the classroom. The result is a "push-pull" conceptualization of the goals for literacy education, with metaphors of function and pleasure alternately occupying the central and peripheral positions on the conceptual continuum.

\section{Conceptual hierarchy.}

Focus Group B's conceptual hierarchy aligned with Lakoff and Johnson's (1980) updown orientation and appeared coherent with the socially-held value that MORE IS UP AND LESS IS DOWN. That is, the LITERACY AS ADAPTATION metaphor represented a "lower level" or "less important" literacy outcome for these teachers, while the LITERACY AS POWER and LITERACY AS A STATE OF GRACE metaphors represented "higher level" or "more important" literacy outcomes. Like the elementary teachers' conceptual continuum, Focus Group B's conceptual hierarchy may also be indicative of the secondary teachers' experiences in the classroom. For example, all of the secondary teachers agreed with Molly's suggestion that, "the most basic level of literacy is mere functioning, so that's the level we aim for." Rob added, "If students don't start there, they can't move on to higher levels of literacy, like the appreciation of culture and literature." Jane asserted that, "functional literacy is exactly what the State wants students to learn. You know, the desire for 'accountability.' And the State has kept us from teaching the more important aspects of literacy, like exploring our connections to our language and our past, because we're always sitting in meetings dissecting test scores." Like the elementary teachers' perception of the functional aspect of literacy as highly valued by the State, Focus Group B's relegation of the LITERACY AS ADAPTATION metaphor to the bottom rung of their conceptual hierarchy may suggest its perceived lack of value for these teachers.

An additional aspect of Focus Group B's conceptual hierarchy was further suggested by the teachers' extended descriptions of the two "higher level" literacy metaphors, and so warrants comment. As reported in Table 1, the LITERACY AS POWER metaphor did occur, albeit with less frequency than the other two conceptual metaphors, but was only used in reference to marginalized student populations. For example, Jane's remark that literacy education can "overturn oppression" was conceptualized by the group as an educational outcome directly benefitting students who are "already in the minority," or those who are "at risk" or "nearly illiterate." In contrast, the LITERACY AS A STATE OF GRACE metaphor was described solely in terms of the dominant culture, with the participants stressing the importance of teaching canonical and Western literature as a means of helping "students connect to the writing of the past" and enabling them to "appreciate who they are." There was no evidence that the LITERACY AS POWER metaphor applied to students in the dominant culture, and no evidence that the LITERACY AS A STATE OF GRACE metaphor referred to instruction using non-mainstream or nonWestern literature.

\section{The functional aspect of literacy.}

While the dissimilarities between the two focus groups' conceptual orientations may indicate differences between their value systems as elementary and secondary school teachers, there was one prominent metaphor common to both groups: the LITERACY AS ADAPTATION metaphor. The primacy of this conceptual metaphor seems to suggest a shared understanding of the current culture of U.S. education. That is, while each group organized its value system differently (e.g., Focus Group A's central-peripheral orientation and Focus Group B's up-down 
orientation), their shared use of the LITERACY AS ADAPTATION metaphor implies that both value systems are coherent with the broader culture of standards-based educational reform today, particularly in its concerns for (a) promoting "the basics" of literacy instruction across the spectrum of public schooling, as well for (b) achieving higher levels of educational accountability. Further, the similar ways in which participants in both groups appeared to conceptually counter what they viewed as the State's primary goal of promoting the functional aspect of literacy through their use of alternate metaphors (e.g., Focus Group A's search for "balance" between the functional and pleasurable aspects of literacy and Focus Group B's marginalization of functioning in society as a "less" important outcome for literacy learning), may suggest a shared dissatisfaction with the values and outcomes they view as promulgated by recent legislative mandates for K-12 literacy education and the attendant increase in State and federal testing policies under the auspices of the 2001 No Child Left Behind Act.

\section{Conclusions and Implications: The Metaphors We Might Teach By}

This study found evidence of the three literacy metaphors identified in Scribner's (1984/ 1988) taxonomy occurring in the language used by the six participants. In addition, one other conceptual metaphor-LITERACY AS PLEASURE-was identified in the elementary teachers' focus group discussion data. It was further suggested that the primacy of the LITERACY AS ADAPTATION metaphor apparent in both of the focus groups' discussion data indicated the teachers' awareness of the heightened U.S. expectations for "functional" literacy learning in the $21^{\text {st }}$ century. Their use of alternate conceptual metaphors to highlight other, perhaps less quantifiable, values and outcomes of literacy learning (e.g., increased personal pleasure for Focus Group A, heightened connections to culture, language, and literature for Focus Group B) can be read as running counter to the more pragmatic values and outcomes typically associated with the LITERACY AS ADAPTATION metaphor. As such, these other metaphors may be viewed as offering ideological alternatives to what appears as the default and deficit logic shaping standards-based educational reform today: U.S. literacy levels are "disturbingly low," which, in turn, "bodes ill for the ability of Americans to meet the demands placed upon them by citizenship in a democratic republic and the challenges of a highly competitive global marketplace of goods, services, and ideas" (Common Core State Standards, Appendix A, p. 4), and thus justifies raising standards and increasing testing.

As explained earlier, case studies are limited in their ability to make claims beyond the specific research context. Instead, their usefulness lies in the exploratory process they undertake and the detail-rich descriptions they provide, which can, in turn, raise new issues for teacher research and practice. In the course of this study, two related issues have surfaced and speak to the future of literacy education; that is, to the metaphors we might teach by.

The first issue was raised by Focus Group B's discussion of the LITERACY AS POWER metaphor, where literacy's power is imagined as something that can "overturn oppression" but only in the narrowest of educational applications and only for those students already labeled as "marginal" or "minority" or "nearly illiterate" by the educational institution. Power in this sense is assumed to be the possession of the dominant class, presumably extended to the powerless in the course of a "good" education, but remaining uninterrogated as to its meaningfulness for those in power. As a result, literacy's potential to transform power relations as they currently exist in society, not just on the margins but also at the center, is too easily muted. A differently conceived LITERACY AS POWER metaphor we might teach by, then, would be one in which we acknowledge, teach, and critique the idea that hegemonic sociopolitical relations require just as 
much power for enforcement as transformative projects require power for change. Setting the LITERACY AS POWER metaphor more fully within critical pedagogical practices might encourage the sort of re-conceptualization of power that educational theorists have long called for (Delpit, 1996; Gee, 2004; Janks, 2009; Mitchell \& Weiler, 1991).

The second issue was raised by Focus Group A's frequent use of the LITERACY AS PLEASURE metaphor. The elementary teachers' conceptualization of LITERACY AS PLEASURE can be read as a counter-narrative to what they see as a deleterious effect of recent U.S. educational reforms; namely, the subjugation of literacy's affective aspects in favor of the more pragmatic values associated with school-based literacy learning. The LITERACY AS PLEASURE metaphor, which extends Scribner's (1984/1988) taxonomy and offers an alternate way of conceiving literacy within the current context of increased legislative mandates and testing policies, also posits a metaphor we might teach by, one that approximates the reasons the teachers cited for becoming literacy educators in the first place: Their felt experiences as literacy learners and their belief in the value of pleasure for increasing student motivation and success. In this sense, the LITERACY AS PLEASURE metaphor resonates with recent scholarship focused on self-efficacy and learning (Bandura, 2008; Guthrie \& Wigfield, 2000; Vacca, 2006) as well as culturally relevant and responsive pedagogies (Gay, 2000; Ladson-Billings, 1995; Lipman, 1995) in their shared claims for creating meaningful classroom experiences that promote academic success for all students.

Both issues raised return us to Scribner's (1984/1988) argument about the links between what we think about literacy - what literacy is, what we expect literacy can do for individuals and societies - and how these conceptualizations shape the "substance and style of educational programs" (p. 71). In other words, claims about which aspects of literacy should be advanced over others are ultimately claims about our expectations for K-12 literacy education itself, outcomes that drive decisions about curriculum and impact classroom instruction. LadsonBillings' (1995) argument for the usefulness of culturally relevant teaching, described as a "pedagogy of opposition, not unlike critical pedagogy but specifically committed to collective, not merely individual, empowerment" (p. 160), refocuses attention on the social and contextualized dimensions of literacy, aspects and values that appear consistent with both of the teacher focus groups' use of alternate metaphors to express educational outcomes they view as increasingly overlooked. Embedded in the call for more culturally relevant teaching is an insistence to not only provide students with opportunities for academic success, but to also engender in them "cultural competence," or the formation of values, attitudes, and behaviors in step with a diverse U.S. society, and a "critical consciousness through which they challenge the status quo of the current social order" (Ladson-Billings, p. 160). In these ways, culturally responsive teaching aligns with the elementary teachers' attention to the affective goals of learning, including the personal pleasure that underwrites an individual's relationship with literacy, and with the secondary school teachers' recognition of the role literacy plays in the transmission of history, culture, and language, as well as the maintenance or transformation of power relations in society.

Concerns about declining national literacy rates, about schools that are not meeting the needs of diverse students and students who are not prepared to compete in today's globalized marketplace are, of course, not confined to U.S. contexts. Such concerns have not only recently initiated a "reorganisation of the public sector and the civil services, including education" (Luke, 1998, p. 308) in many English-speaking countries, but have also shifted public discourse about education generally, a discourse now "dominated by a language of test scores and economic 
competitiveness" (Rose, 2009). "It matters a great deal how we collectively talk about education," Rose asserts, "for that discussion both reflects and, in turn, affects policy decisions about what gets taught and tested, about funding, about what we expect schooling to contribute to our lives" (p. 5). Our Western tendency to explain educational problems as "systems problems" and not as social ones, Luke argues, "may lead us down blind alleys, missed opportunities, and poor investment of our scarce time, resources, and money" (p. 313). Both theorists remind us of the constitutive power of language, underscoring the importance of better understanding the metaphorical nature of literacy education, not only in terms of the metaphors we currently teach by but also the ones we might teach by, in our efforts to create new realities and contribute to a future productively transformed. 


\section{References}

Armstrong, S. L., Davis, H. S., \& Paulson, E. J. (2011). The subjectivity problem: Improving triangulation approaches in metaphor analysis studies. International Journal of Qualitative Methods, 10(2), 151-163.

Armstrong, S. L. (2008). Using metaphor analysis to uncover learners' conceptualizations of academic literacies in postsecondary developmental contexts. International Journal of Learning, 15(9), 211-218.

Bandura, A. (2008). Toward an agentic theory of the self. In H. Marsh, R.G. Craven, \& D.M. McInerney (Eds.), Self-processes, learning, and enabling human potential: Dynamic new approaches (pp. 15-49). Charlotte, NC: Information Age Publishing.

Bhattacharya, U. (2011). The 'West' in literacy. Berkeley Review of Education, 2(2), 179-198.

Brickell, H. M. (1983). Schools without standards. Educational Leadership, 41(2), 30-31.

Cameron, L., \& Low, G. D. (Eds). (1999). Researching and applying metaphor. Cambridge, UK: Cambridge University Press.

Cawelti, G. (1983). Mobilizing the nation. Educational Leadership, 41(2), 33.

Cervero, R. M. (1985). Is a common definition of adult literacy possible?" Adult Education Quarterly, 36(1), 50-54.

Condor, S., \& Antaki, C. (1997). Social cognition and discourse. In T.A. van Dyjk (Ed.), Discourse as Structure and Process (pp. 320-347). London, UK: Sage Publications.

Cortazzi, M., \& Jin, L. (1999). Bridges to learning: Metaphors of teaching, learning and language. In L. Cameron \& G. Low (Eds.), Researching and applying metaphor (pp. 149-176). New York, NY: Cambridge University Press.

de Guerrero, M., \& Villamil, O. S. (2002). Metaphorical conceptualizations of ESL teaching and learning. Language Teaching Research, 6(2), 95-120.

Delpit, L. (1996). Other people's children: Cultural conflict in the classroom. New York, NY: The New Press.

Flower, L. (1994). The construction of negotiated meaning: A social cognitive theory of writing. Carbondale, IL: Southern Illinois University Press.

Gay, G. (2000). Culturally responsive teaching: Theory, research, and practice. New York, NY: Teachers College Press.

Gee, J. P. (2004). Situated language and learning: A critique of traditional schooling. New York, NY: Routledge.

Guthrie, J. T., \& Wigfield, A. (2000). Engagement and motivation in reading. In M.L. Kamil, P.B. Mosenthal, P.D. Pearson, \& R. Barr (Eds.), Handbook for reading research: Volume 3 (pp. 403-422). Mahwah, NJ: Erlbaum.

Heller, R., \& Greenleaf, C. L. (2007). Literacy instruction in the content areas: Getting to the core of middle and high school improvement. New York, NY: Alliance for Excellent Education.

Hlebowitsh, P. (1990). Playing power politics: How A nation at risk achieved its national stature. Journal of Research and Development in Education, 23(2), 82-88.

H.R. 1804-103rd Congress: Goals 2000: Educate America Act. (1993). In GovTrack.us (database of federal legislation). Retrieved from http://www.govtrack.us/congress/bill.xpd?bill=h103-1804.

H.R. 1-107th Congress: No Child Left Behind Act of 2001. (2001). In GovTrack.us (database of federal legislation). Retrieved from http://www.govtrack.us/congress/bill.xpd?bill=h107-1. 
Hunt, S. L., \& Staton, A. Q. (1996). The communication of educational reform: A nation at risk. Communication Education, 45(3), 271-292.

Janks, H. (2009). Literacy and power. New York: Routledge.

Ilsley, P. J., \& Stahl, N. P. (1993). Reconceptualizing the language of adult literacy. Journal of Reading, 37(1), 20-27.

Keller-Cohen, D. (1993). Rethinking literacy: Comparing colonial and contemporary America. Anthropology and Education Quarterly, 24(4), 288-307.

Kovesces, Z. (2002). Metaphor: A practical introduction. Oxford, UK: Oxford University Press.

Ladson-Billings, G. (1995). But that's just good teaching! The case for culturally relevant teaching. Theory into Practice, 34(3), 159-165.

Lakoff, G., \& Johnson, M. (1980). Metaphors we live by. Chicago, IL: University of Chicago Press.

Levin, T., \& Wagner, T. (2006). In their own words: Understanding student conceptions of writing through their spontaneous metaphors in the science classroom. Instructional Science 34(3), 227-278.

Lipman, P. (1995). "Bringing out the best in them": The contribution of culturally relevant teachers to educational reform. Theory into Practice, 34(3), 202-208.

Littlemore, J., \& Low, G. D. (2006). Metaphoric competence and communicative language ability. Applied Linguistics, 27(2), 268-294.

Low, G. D., \& Todd, Z. (2010). Guidelines for good practice in metaphor analysis. In L. Cameron \& R. Maslen (Eds.), Metaphor analysis: Research practice in applied linguistics, social sciences and the humanities (pp. 217-229). London, UK: Equinox.

Luke, A. (1998). Getting over method: Literacy teaching as work in new times. Language Arts, 75(4), 305-313.

Malicky, G. V., \& Norman, C. A. (1995). Perceptions of literacy and adult literacy programs. Alberta Journal of Educational Research, 12(1), 63-83.

Mason, J. M., \& Allen, J. (1986). Literacy, schools and society: Access and excellence. Educational Review, 40(3), 259-275.

Merriam, S. B. (1988). Case study research in education: A qualitative approach. San Francisco, CA: Jossey Bass.

Mitchell, C., \& Weiler, K. (1991). Rewriting literacy: Culture and the discourse of the other. New York, NY: Bergin \& Garvey.

National Commission on Excellence in Education. (1983). A nation at risk: The imperative for educational reform. Washington, D.C.: U.S. Government Printing Office.

National Governors Association Center for Best Practices, Council of Chief State School Officers. (2010). Common Core State Standards for English Language Arts and Literacy in History/Social Studies, Science, and Technical Subjects, Appendix A. Washington, D.C.: National Governors Association Center for Best Practices. Retrieved from http://www.corestandards.org/assets/Appendix_A.pdf

Patton, M. Q. (2001). Qualitative research and evaluation methods (2nd ed.). Thousand Oaks, CA: Sage Publications.

Paulson, E. J., \& Armstrong, S. L. (2011). Mountains and pit bulls: Students' metaphors for college transitional reading and writing. Journal of Adolescent and Adult Literacy, 54(7), 494-503.

Paulson, E. J. (2006). Of medicine and rocket science: Metaphors that shape the field of literacy education. American Reading Forum Online Yearbook, 2006. Retrieved from http:// 
www.americanreadingforum.org/Yearbooks/06_yearbook/html/arf_06_paulson.htm

Rose, M. (2009). Why school? Reclaiming education for all of us. New York, NY: The New Press.

Salinger, T. (n.d.). Addressing the 'crisis' in adolescent literacy. U.S. Department of Education (ED), Office of Elementary and Secondary Education, Smaller Learning Communities Program (Contract Number ED-07-CO-0106). Hernden, VA: EDJ Associates, Inc.

Retrieved from http://www2.ed.gov/programs/slcp/finalcrisis.pdf

Scribner, S. (1984/1988). Literacy in three metaphors. In E. Kintgen, B. Kroll, \& M. Rose (Eds.), Perspectives on Literacy (pp. 71-81). Carbondale, IL: Southern Illinois University Press. (Reprinted from the American Journal of Education, 93, 6-21.)

Sutherland, S. (2010). Unsettling a metaphor we teach by: A hybrid essay on WAC students as 'immigrants'. The WAC Journal, 21, 53-68.

Swope, K. \& Miner, B. (Eds.) (2000). Failing our kids: Why the testing craze won't fix our schools. Milwaukee, WI: Rethinking Schools, LTD.

Trimbur, J. (1991). Literacy and the discourse of crisis. In R. Bullock \& J. Trimbur (Eds.), The politics of writing instruction: Postsecondary (pp. 277-296). Portsmouth, NH: Boynton/Cook.

Williams, K. (2003). Literacy and Computer Literacy: Analyzing the NCR's Being Fluent with Information Technology. The Journal of Literacy and Technology, 3(1). Retrieved from http://www.literacyandtechnology.org/volume3/literacy.katewilliams.pdf

Vacca, R. T. (2006). They can because they think they can. Educational Leadership, 63(5), 5659.

VanWynsberghe, R., \& Khan, S. (2007). Redefining case study. International Journal of Qualitative Methods, 6(2), 80-94.

\section{Author Biography}

Connie Kendall Theado is an Associate Professor in the School of Education at the University of Cincinnati, where she also serves as the coordinator for the Literacy and Second Language Studies Program and the Postsecondary Literacy Instruction Graduate Certificate Program. Her research interests include the history and politics of literacy testing, particularly in high-stakes contexts, K-12 teacher preparation, and postsecondary developmental education. 


\section{Appendix A}

\section{Written Survey Questions}

1. Describe your history as a teacher (e.g., years of service, grade levels/subjects taught, personal educational background).

2. Briefly describe your history as a learner of school-based literacy. Are there any reportable memories from your educational past where your identity as a literate person was noticeably formed and/or transformed? If so, please share one or two of these memories.

3. How would you define the concept of literacy?

4. In your opinion, what are some of the values (cultural, political) and utilities (personal, occupational) associated with becoming a literate member of U.S. society?

5. How would you describe the public school system's investment in literacy education today? In other words, what values and/or utilities associated with literacy seem to inform the State of Ohio's curricular and assessment guidelines for student acquisition of school-based literacy?

\section{Appendix B}

\section{Focus Group Questions}

1. Tell me about why you chose to become a teacher, particularly a literacy teacher.

2. How would you define literacy?

3.What are some of the values (cultural, political) and utilities (personal, occupational) associated with becoming a literate member of U.S. society?

4. How would you define illiteracy?

5. What do you view as the consequences (cultural, political, personal, occupational) of being illiterate in a society that values literacy?

6. How would you describe the social value of your daily work as a literacy educator? That is, how do you see yourself and/or your pedagogical practices impacting the lives of your students?

7. What are some of the specific goals or expectations you hold for your students with regard to their acquisition of school-based literacies? 